\title{
Protection of glazed tiles in ancient buildings of China
}

\author{
Dilireba Adili, ${ }^{1,2}$, Jing Zhao ${ }^{1 *}$, Lu Yang $^{2}$, Peng Zhao ${ }^{3}$, Cong Wang $^{3}$ and Hongjie Luo ${ }^{4}$
}

\begin{abstract}
Silicon materials containing fluorine with similar nanoscale particles (SIC-1 and SIC-2) and organic silicon resin materials with excellent hydrophobicity (SIC-3) were selected to deal with glaze shedding and damage of glazed tiles in ancient buildings. Experimental analysis on the hydrophobic properties and microscopic morphology of the materials, as well as the changes of the surface temperature and the shedding rate of glaze layer after adding protective materials indicated: the thermal expansion differences and the shedding rate of glaze layer following sharp changes of temperature and humidity had been decreased. In particular, with the help of protective material SIC-2, a silicon material containing fluorine, there was the smallest change in the color of the glaze layer; the hydrophobic property and the water vapor transmittance of matrix were also improved. In a nutshell, the results showed that the addition of these protective materials alleviated the effects of radical temperature and humidity changes on glaze layer and matrix, and effectively delayed the occurrence of glaze shedding.
\end{abstract}

Keywords: Protection of glazed tiles, Shedding of glaze layer, Silicon materials containing fluorine, Hydrophobic property, Water vapor transmittance

\section{Introduction}

In the 4th Century AD, China began to use glazed products as a unity of pragmatism and art in architecture. Since then, glaze has become inseparable from architecture with its gorgeous color and preferable waterproof performance [1]. The most typical example is the ancient glazed tiles in Beijing Palace Museum, with exquisite modeling, varieties of patterns and themes.

At present, large areas of glaze shedding and other serious damages appeared on magnificent ancient glaze tiles in the Palace Museum. Yanxi Tang of Yangxin Hall is taken as the most typical example, and the composition, morphology, thermal properties and others properties of glaze layer and matrix were analyzed. Results showed that under the cyclic changes of summer heat and sudden rain conditions, uneven distribution of thermal stress on the interface between glaze layer and matrix became one

\footnotetext{
*Correspondence: zhaojing1003@126.com

${ }^{1}$ Ancient Ceramics Research Center, Shanghai Institute of Ceramics

Chinese Academy of Sciences, Shanghai 200050, China

Full list of author information is available at the end of the article
}

of the most important factors for the shedding of glaze layer [2].

Considering that the glaze shedding on ancient buildings was resulted from sharp temperature and humidity changes, the prevention of "drastic changes" should be deemed as a crucial solution to the problem. Thus, in addition to traditional physical and mechanical cooling methods, the method of applying appropriate protective coatings can also be selected to decrease the residence time of rain on the glazed tiles.

Although few literatures focus on the protection for glazed tiles, there have been some studying the maintenance of similar materials such as potteries and ancient stones. For instance, Primal SF, Paraloid B72, acrylates [3-7] and composite materials [8] as B72 and Remmers300 were employed extensively. Meanwhile, hydrophobic nanomaterials with tetraethoxysilane (TEOS) and hydroxyl-terminated polydimethylsiloxane (PDMS) in the presence of nonionic surfactants were applied to stone restoration $[9,10]$; several modified ethyl silicate consolidants [11], organosilane consolidants [12-14], copolymers of fluorinated acrylates, methacrylates with
Springer Open

\footnotetext{
(c) The Author(s) 2020. This article is licensed under a Creative Commons Attribution 4.0 International License, which permits use, sharing, adaptation, distribution and reproduction in any medium or format, as long as you give appropriate credit to the original author(s) and the source, provide a link to the Creative Commons licence, and indicate if changes were made. The images or other third party material in this article are included in the article's Creative Commons licence, unless indicated otherwise in a credit line to the material. If material is not included in the article's Creative Commons licence and your intended use is not permitted by statutory regulation or exceeds the permitted use, you will need to obtain permission directly from the copyright holder. To view a copy of this licence, visit http://creativecommons.org/licenses/by/4.0/. The Creative Commons Public Domain Dedication waiver (http://creativecommons.org/publicdomain/zero/1.0/) applies to the data made available in this article, unless otherwise stated in a credit line to the data.
} 
unfluorinated acrylates, methacrylates and vinyl ethers [15-21], as well as polyhydroxybutyrate and poly-L-lactide [22] were synthesized; the properties on adhesion, water repellency and intrinsic photostability of these materials were compared.

However, when these materials are used in glazed tiles, it is difficult for them to penetrate into the matrix and a thin film on the surface could be formed, which would result in the color deepening and poor air permeability of the protected glazed tiles. In this study, fluoride silicon materials and hydrophobic nanomaterial with tetraethoxysilane (TEOS) and hydroxyl-terminated polydimethylsiloxane (PDMS) with excellent hydrophobic property have been selected. Furthermore, the molecular structure and microstructure of the protective materials as well as the protected properties of glazed tiles have been analyzed respectively. The results provide valuable information for preventing or slowing down the continuous shedding of the glaze in ancient architectures.

\section{Experiment}

\section{Glazed tile samples}

Due to the rarity, scarcity and importance of information contained in the glazed components of ancient buildings in Palace Museum, the glazed tile fragments with incomplete glaze layer and no detailed chronology of Yanxi Tang in Yangxin Hall are selected.

\section{Protective materials}

Protective materials, SIC-1 and SIC-2, are synthesized by Stober Method [23]. Specifically, they are reacted for $8 \mathrm{~h}$ with fluorine-containing polymer $1 \mathrm{H}, 1 \mathrm{H}, 2 \mathrm{H}$, $2 \mathrm{H}$-perfluorooctyl triethoxylsilane $(0.5 \mathrm{~g})$ and $\mathrm{SiO}_{2}$ particles [24] in different particle sizes at the catalyzing of ethyl orthosilicate $(5 \mathrm{ml})$ with ethanol or water. These are solvent-based and water-based materials with similar nanoscale particles and main components of $\mathrm{F}$ and Si elements. Meanwhile, SIC-3 is a hybrid material prepared by ethyl orthosilicate and hydroxy-terminated polydimethylsiloxane $[25,26]$. The materials are placed on a $75 \times 25 \times 1 \mathrm{~mm}^{3}$ slide to form a film, and the molecular structure and thermal stability are tested.

After the protective materials with a concentration of $5 \%$ are sprayed to the surface of glazed tile samples, the color, surface hydrophobicity, surface micromorphology and glaze shedding rate under drastic changes of temperature and humidity are tested respectively.

\section{Test conditions and simulation test methods}

Infrared spectrum (FTIR-ATR): The infrared spectrum curve of the protective materials is tested with the ATR attachment of American Thermo Scientific Nicolet iS50 Fourier infrared spectrometer (FTIR). The wavelength range is $500-4000 \mathrm{~cm}^{-1}$; the spectral resolution is greater than $0.09 \mathrm{~cm}^{-1}$, and the wave number accuracy is greater than $0.01 \mathrm{~cm}^{-1}$.

Micromorphology: JSM-6700Fscanning electron microscopy with energy dispersive X-ray (SEM-EDX) of JEOL Company in Japan is adopted. Scanning electron microscope is used to observe the microstructure of glaze layer and the surface of the glaze matrix, and the distribution of related components is determined by the energy dispersion spectrometer.

Color change: Color changes of the glaze surface and the matrix before and after the addition of protective materials are tested by CM-700d spectrophotometer (Japan). The data L*, a*, b*in CIE L*a*b* color model with artificial daylight $6500 \mathrm{~K}$ are tested, in which the $\mathrm{L}$ means the lightness value, $\Delta \mathrm{L}$ is the lightness difference, the a is the value of red and green color changes, $+a$ is the increase of red and $-a$ is the increased of green, $b$ is the value of yellow and blue changes, $+b$ is the increased of yellow and $-b$ is the increased of blue. The color changes of samples are calculated by the formula $\Delta \mathrm{E}=\sqrt{(\Delta \mathrm{L})^{2}+(\Delta a)^{2}+(\Delta b)^{2}}$, normally, the materials should not be selected when $\Delta \mathrm{E}>5$.

Hydrophobicity: JC2000C1 contact angle measuring instrument (Shanghai Zhongchen Digital Technic Apparatus Co., Ltd.) with the suspension drop method is used to test the changes of contact angle in glaze layer and matrix before and after the addition of protective materials.

Water vapor permeability: According to the "hygrothermal performance of building materials and productsDetermination of water vapor transmission properties" [27], water vapor is made to flow from the high humidity to the low humidity through the surface materials on the water container. Calculate the mass change of water vapor and then calculate the water vapor diffusion coefficient according to the formula:

$$
\mu=(\mathrm{P} \times \delta \mathrm{L}) /[\mathrm{M} /(\mathrm{t} \times \mathrm{S} \times \mathrm{d})]
$$

In this formula, $\mathrm{t}$ stands for the time (h), $\mathrm{M}$ for vapor diffusion weight $(\mathrm{kg}), \mathrm{S}$ for the area $\left(\mathrm{m}^{2}\right), \mathrm{P}$ for water vapor pressure at tested temperature $(\mathrm{Pa}), \mathrm{d}$ for the tested material thickness $(\mathrm{mm}), \delta \mathrm{L}$ for the constant of water vapor in the air, is $7.02 \times 10^{-7}(\mathrm{~kg} / \mathrm{m} \mathrm{h} \mathrm{Pa})$; the greater $\mu$ value of resistance to water vapor diffusion coefficient is, the stronger the ability to resist the diffusion of water vapor is, and the worse the material permeability is. As the glaze layer has preferable hydrophobicity and density, permeability test is mainly used in glaze matrix. The concrete experiment method is as follows: cement gum is adopted to seal the contact interface of protected matrix and the water container; the diameter and thickness of 
the matrix through which the vapor passes are $25 \mathrm{~mm}$ and $2 \mathrm{~mm}$ respectively; put the container in a chamber with a constant temperature of $90{ }^{\circ} \mathrm{C}$; weigh the mass change of the container within a certain period of time, and calculate the water vapor resistance diffusion coefficient $\mu$ value according to Formula (1).

Surface temperature: Drastic change of environmental temperature and humidity is one of the main factors for the loss of glaze, thus, it is particularly essential to monitor the change of surface temperature of samples treated with protective materials. T450sc infrared thermal imager of American FLIR is adopted to obtain the temperature distribution of the whole area, with the infrared resolution of $320 \times 240$ pixels and the wavelength range of $7.5 \sim 14$ microns.

Thermal expansion coefficient changes: Germany Netzsch DIL402C thermal expansion instrument is adopted and the test temperature is $25^{\circ} \mathrm{C} \sim 300^{\circ} \mathrm{C}$, which is close to the natural environment. Meanwhile, the thermal stability of the protective materials is maintained. The heating rate is $5 \mathrm{~K} / \mathrm{min}$; the flow rate of $\mathrm{N}_{2}$ is $2 \mathrm{~L} / \mathrm{h}$ and the mandrel pressure is $0.4 \mathrm{~N}$.

Glazing shedding rate: In order to trigger the damage of glaze layer caused by high temperature and sudden outdoor rainfall in summer, which can be commonly observed in ancient glaze components, the modern glaze samples protected by different materials are selected for the test after being dried in an oven at $100{ }^{\circ} \mathrm{C}$ and immersed in a mixed solution of ice water at $0{ }^{\circ} \mathrm{C}$ for $4 \mathrm{~h}$ respectively for several times. The repeated cycle of the samples and the changes of the glaze layer are recorded. The number of ancient glaze samples for each group is no less than five pieces, with a size of about $50 \times 50 \times 15$ $\mathrm{mm}^{3}$. The changes to morphology and deglaze of the samples under different experimental conditions are also recorded.

Professional image analysis software is adopted to calculate the loss rate of glaze surface $(\sigma / \%)$. The ratio of pixel between the shedding part of the glaze image $\left(\mathrm{S}_{\text {shedding glaze }}\right)$ and the whole original glaze surface $\left(\mathrm{S}_{\text {original }}\right.$ glaze) is used for comparative analysis. The specific calculation method is: $\sigma(\%)=\mathrm{S}_{\text {shedding glaze }} / \mathrm{S}_{\text {original glaze }} \times 100 \%$.

\section{Results and discussion}

\section{Performance analysis of protective materials}

Microstructure and molecular structure of the selected protective materials are tested by FTIR-ATR and SEM-EDX. It is found in the molecular structure of the tested materials that $\mathrm{Si}-\mathrm{O}-\mathrm{Si}$ absorption peaks of SIC-1 and SIC-2 in Fig. 1 are obverted at $1050 \mathrm{~cm}^{-1}$ and $1070 \mathrm{~cm}^{-1}$ respectively; typical stretching vibration

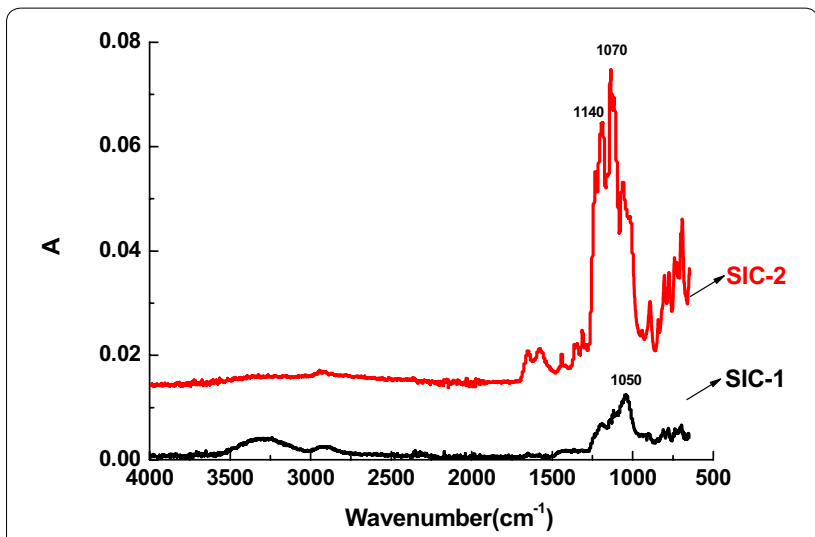

Fig. 1 Infrared spectrum curves of SIC-1 and SIC-2

peak of C-F occurs in $1200 \mathrm{~cm}^{-1}$ and $1140 \mathrm{~cm}^{-1}$, among which the C-F stretching vibration peak intensity of SIC-2 is higher. After observing the nanoclusters with granular distribution on the surface of SIC-1 material after curing in Fig. 2, we can find that the particle diameter is mainly $50-200 \mu \mathrm{m}$, including the ones of $150 \mu \mathrm{m}$ with the largest proportion; protuberant particle composition is mainly dominated by F, Si elements, and the height of the raised is about $70 \mu \mathrm{m}$.

The protrusion structure is similar to that of nanoscale particles in lotus leaf, where water on these tiny particles does not spread to the other directions of the materials' surface, but tends to form spheres (as shown in Fig. 2a).There is granular distribution on the surface of SIC-2, with particle diameter being $10-80 \mu \mathrm{m}$. The components of the protuberant particles are mainly $\mathrm{F}$ and Si elements (Fig. 3), with a height of about $38 \mu \mathrm{m}$. Compared with the SIC-1, the smaller the diameter of protuberant particles in SIC-2 is, the better the hydrophobic performance is (Fig. 2b).

Different from fluoride silicon materials of SIC-1 and SIC-2, SEM and infrared spectra of the synthesized silane material SIC-3 in Fig. 4 indicate the organic combination of TEOS hybrid materials with $5 \%$ of hydroxyterminated polydimethylsiloxane. They also show that the stretching vibration absorption peak of $\mathrm{Si}-\mathrm{CH}_{3}$ appears at $1295 \mathrm{~cm}^{-1}$ and $798 \mathrm{~cm}^{-1}$ in the infrared spectrum curve; obvious $\mathrm{Si}-\mathrm{O}-\mathrm{Si}$ absorption broad peak appears in $1070 \mathrm{~cm}^{-1}$.The organic components and inorganic components of the materials are closely combined, and the structure is relatively uniform. The inorganic particles are distributed inside the organic layer, and the size of the particles is about $100 \mathrm{~nm}$ (Fig. 4a). The two phases are well compatible with each other and exhibit good uniformity at the macro level. 


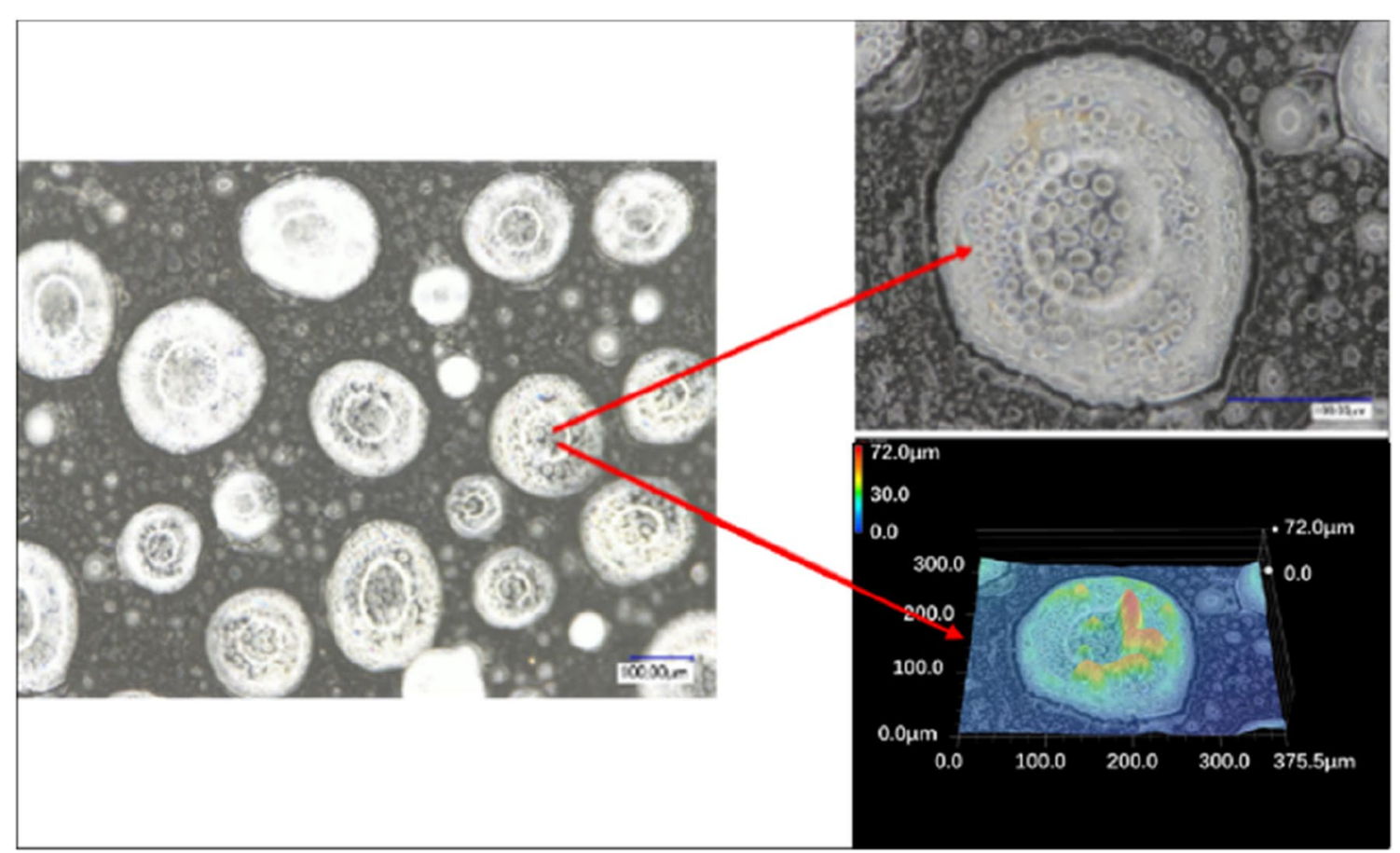

a

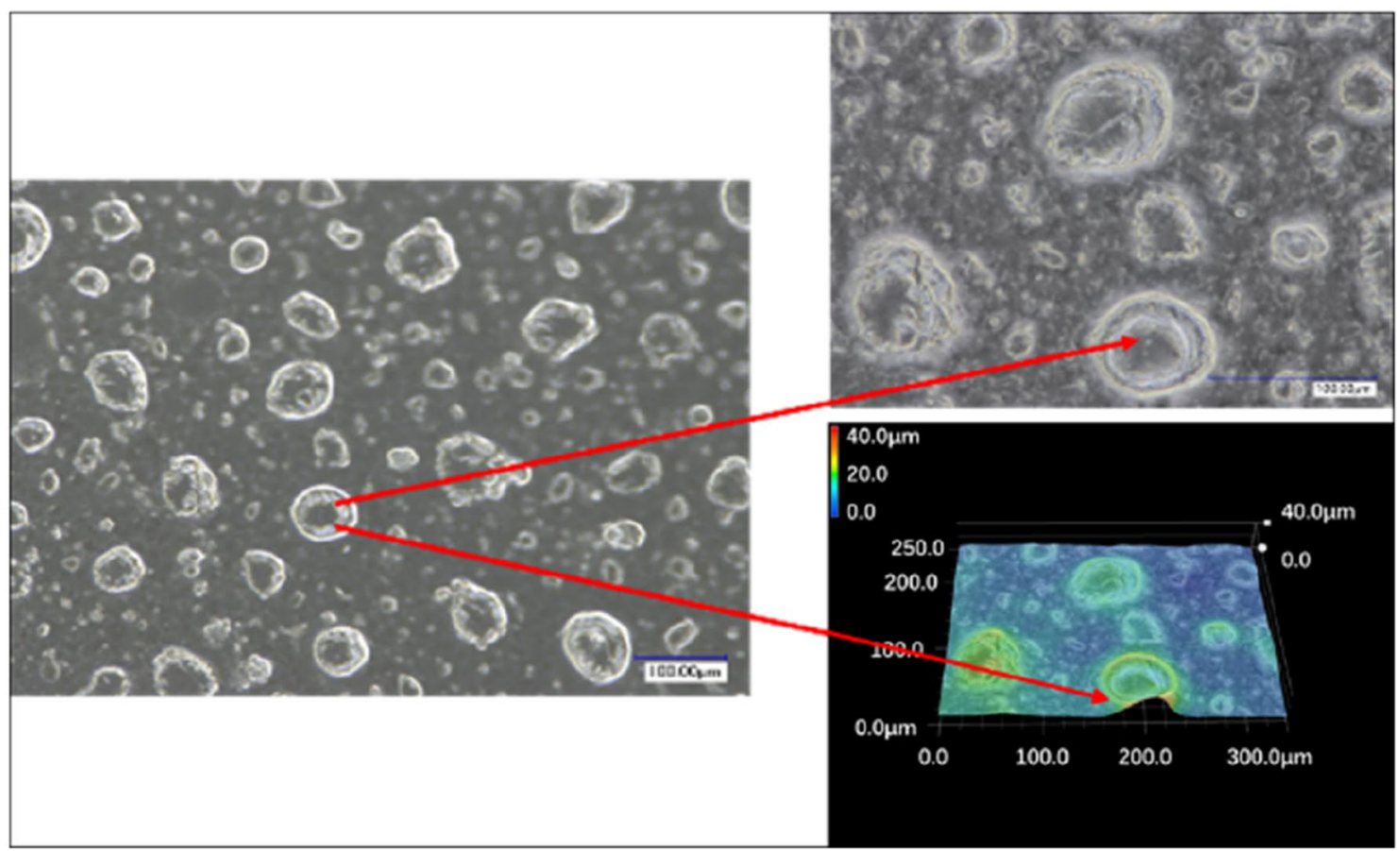

b

Fig. 2 Microstructure of $\mathbf{a} \mathrm{SIC}-1$ and $\mathbf{b} \mathrm{SIC}-2$ materials with depth of field microanalysis

\section{Performance analysis of protective materials applied} to glaze samples

Different protective materials are sprayed to surface of glaze fragments. The curing time of SIC- 1 and SIC-2 is very short, i.e., about 3-5 min, while that of SIC-3 is relatively long, i.e., about $2 \mathrm{~h}$. After the materials are completely cured, the properties of color, hydrophobicity, microscopic morphology, water vapor permeability, as 

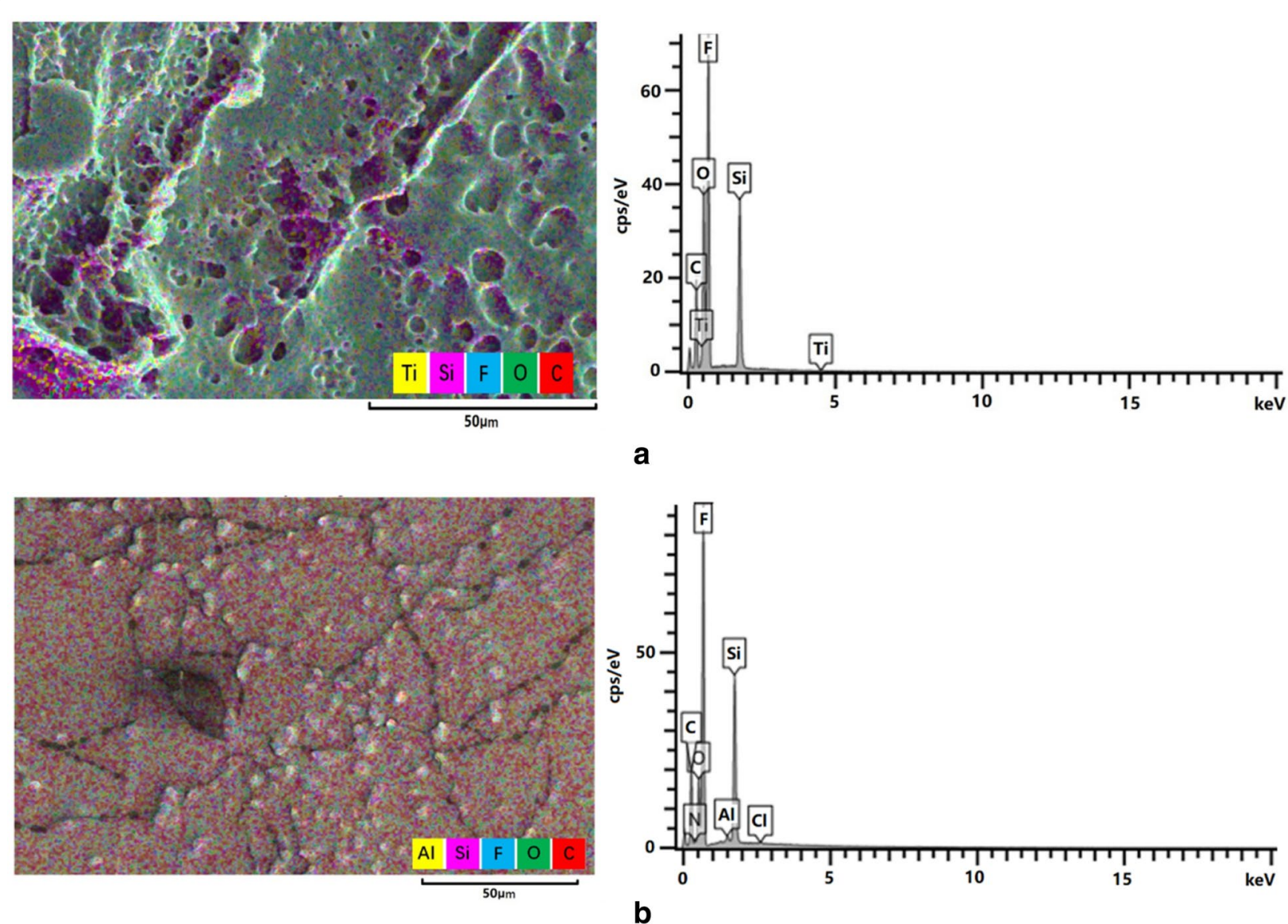

Fig. 3 Microstructure and element distribution of protective materials (a) SIC-1 (b) SIC-2 with SEM-EDX

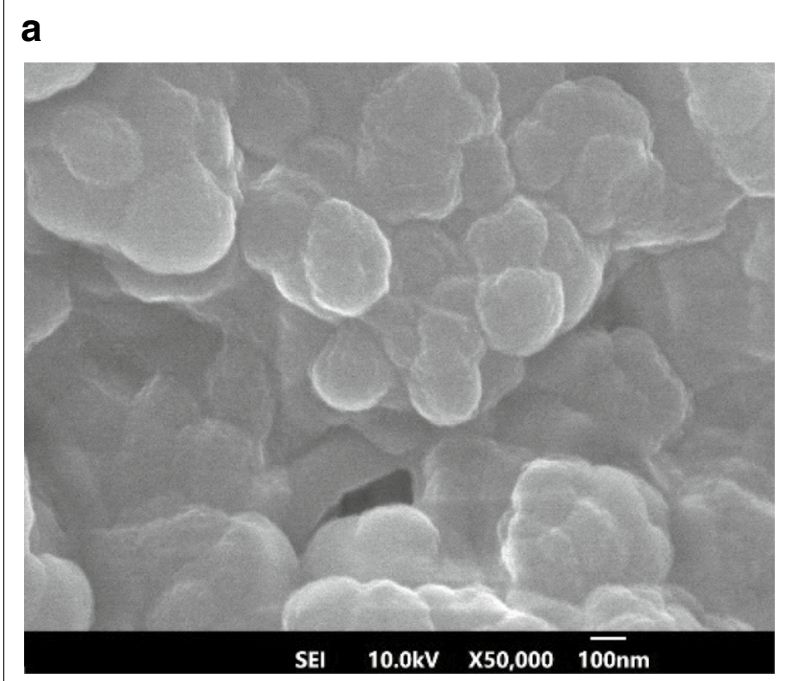

b

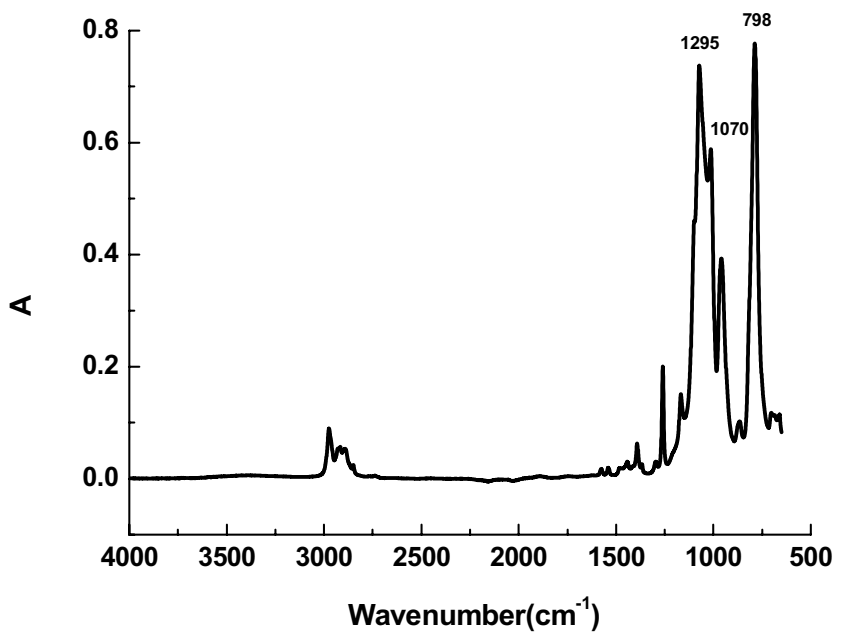

Fig. 4 Microstructure (a) and infrared spectrum curve (b) of SIC-3 material 
Table 1 Color changes of glazed samples protected by materials

\begin{tabular}{lrrrr}
\hline Sample name & \multicolumn{1}{c}{$\mathbf{L}^{*}$} & $\boldsymbol{\Delta a}^{*}$ & $\boldsymbol{\Delta b}^{*}$ & $\boldsymbol{\Delta E}$ \\
\hline SIC-1 glaze layer & -1.32 & 0.70 & 2.87 & 3.23 \\
SIC-2 glaze layer & -1.46 & 0.85 & 1.26 & 2.10 \\
SIC-3 glaze layer & -1.93 & 1.37 & 2.23 & 3.25 \\
SIC-1 matrix & 0.68 & -0.22 & 1.62 & 1.76 \\
SIC-2 matrix & -2.38 & 1.30 & 1.54 & 3.11 \\
SIC-3 matrix & -4.21 & 1.88 & 2.97 & 5.47 \\
\hline
\end{tabular}

well as the surface temperature and glaze shedding rate are observed specifically.

Color change: The color changes of the glaze layer before and after the addition of protective materials are calculated to be $3.23,2.10,3.25$, while those of the matrix are $1.76,3.11$ and 5.47 , respectively. By contrast, the addition of SIC-3 has a greater influence on the color of glaze layer and matrix, especially for the lightness $\Delta \mathrm{L}$ (Table 1 ), the change of SIC-3 matrix is obvious.

Hydrophobicity: During the changing process of protective materials coated on the glaze surface and the matrix, there is a satisfactory compatibility between the protective materials and the glaze samples. For the solid surface treated with protective materials with inhomogeneous chemical compositions, the contact angle of droplets on the surface satisfies the Cassie equation: $\cos \theta=\mathrm{f} 1 \cos \Theta 1+\mathrm{f} 2 \cos \theta 2$. In the equation, $\Theta 1$ and $\Theta 2$ are the contact angles of composition 1 and composition 2 on the ideal surface; $\mathrm{f} 1$ and $\mathrm{f} 2$ are the area fractions of the two components respectively in the whole surface $[28,29]$. The changes of contact angle between the glaze and the matrix after the addition of protective materials are shown in Table 2; the addition of protective materials can improve the hydrophobicity of the matrix after the glaze shedding and the pure matrix surface. Due to the fact that the glaze itself has a higher hydrophobicity and compactness, the addition of protective materials has a smaller impact on the improvement of the glaze hydrophobicity; whereas for the matrix with shedding of glaze and pure matrix, the hydrophobic ability for the surface after the treatment can reach a state consistent with that of the glaze layer (Fig. 5). The newly added protective materials have greatly improved the hydrophobic ability of the samples; the contact angle of the pure matrix has been increased ten times than before, which could play the role of a good barrier to the outside moisture.

Water vapor permeability and microstructure: The water vapor resistance diffusion coefficient $\mu$ value is adopted to detect the water vapor permeability of the glaze samples, especially for the matrix after the addition of protective materials. As to the changes of water vapor

Table 2 Contact angles of the protective materials applied to the glaze surface $\left({ }^{\circ}\right)$

\begin{tabular}{|c|c|c|c|c|c|c|}
\hline \multirow[t]{2}{*}{ Serial number } & \multicolumn{2}{|c|}{ Glaze surface } & \multicolumn{2}{|c|}{ Matrix with shedding of glaze layer } & \multicolumn{2}{|l|}{ Matrix } \\
\hline & $\begin{array}{l}\text { Before } \\
\text { treatment }\end{array}$ & After treatment & $\begin{array}{l}\text { Before } \\
\text { treatment }\end{array}$ & After treatment & $\begin{array}{l}\text { Before } \\
\text { treatment }\end{array}$ & After treatment \\
\hline $\mathrm{SIC}-1$ & 81.33 & 99.44 & 68.71 & 92.16 & 11.20 & 103.06 \\
\hline $\mathrm{SIC}-2$ & 90.32 & 98.02 & 69.24 & 110.43 & 13.86 & 124.47 \\
\hline$S I C-3$ & 93.70 & 98.80 & 71.61 & 111.16 & 14.35 & 108.00 \\
\hline
\end{tabular}

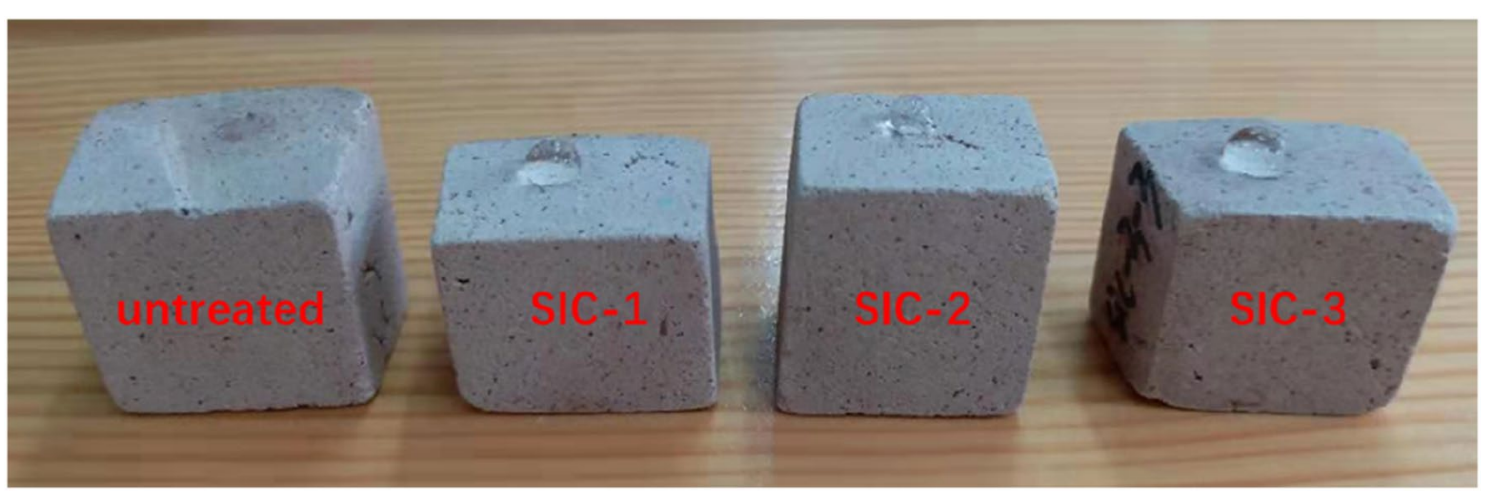

Fig. 5 Hydrophobicity of glazed matrix after treatment 
diffusion after being placed for $52 \mathrm{~h}$, the four curves of the materials' resistance to vapor diffusion before and after the treatment show a nearly linear relationship (Fig. 6); among them, the anti-water vapor coefficient of untreated sample is the largest, while the anti-water vapor coefficient of added materials decreases, and the decreasing degree for SIC-1 and SIC-2 is relatively large. After comparative analysis, the regression equations are fitted by the curves of resistance to water vapor diffusion coefficient $(y)$ and time ( $x$ /hours) of the untreated sample and samples with added materials of SIC-1, SIC-2 and SIC3 , which are $\mathrm{y}=0.2165 \mathrm{x}+0.8322, \mathrm{y}=0.0429 \mathrm{x}+0.0813$, $\mathrm{y}=0.0570 \mathrm{x}+0.2780$ and $\mathrm{y}=0.0784 \mathrm{x}+0.5015$; correlative coefficients $R^{2}$ are 0.9987, 0.9981, 0.9912 and 0.9925; the slopes of these equations are $0.2165,0.0429,0.05700$ and 0.0784 , which means that the anti-vapor diffusion rate of the matrix is relatively small and the permeability of the sample is enhanced.

The reason for the enhancement of the water vapor permeability of matrix after the addition of protective materials has been analyzed, which was speculated to be related to the binding distribution between materials and glaze particles, as shown in Fig. 7c, nanoclusters with claw structure are formed on the surface of the glaze matrix after adding SIC-2 materials; these nanoislandstructured materials do not change the original particle bonding mode of the matrix, and the pores between the particles are clearly visible. Due to the excellent hydrophobicity of the added materials with the nanocluster structure (see Table 2), the absorption of water vapor between particles decreases, and the change rate of water vapor through the pores of particles is further enhanced, specifically indicated in the results of increased water vapor transmission rate of the samples after the addition of protective materials.

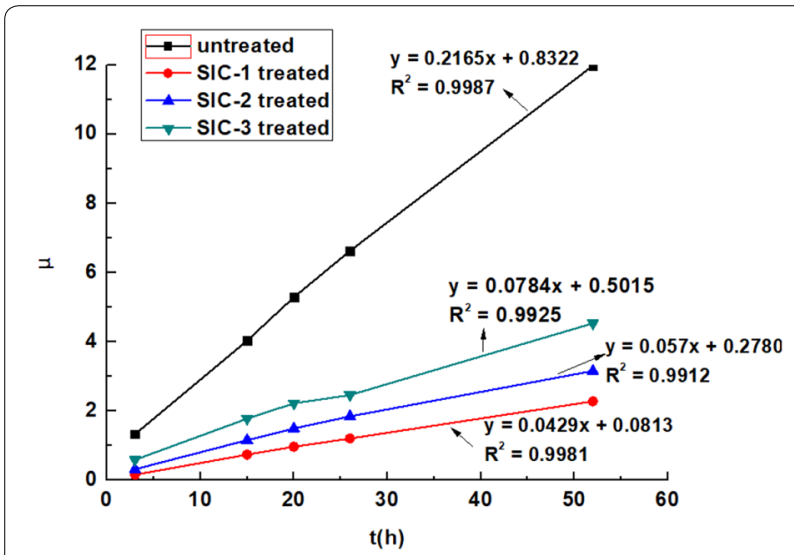

Fig. 6 The samples' changing curves of resistance to water vapor diffusion
Surface temperature and thermal expansion coefficient: In order to avoid the influence of temperature changes on the individual differences of glaze samples, ancient glaze samples with one half untreated and the other half treated with protective materials are adopted in the experiment. Take a sample with the left side untreated and the right side treated with SIC-2 (Fig. 8) as an example. Infrared thermography is used to test the surface temperature changes from the high temperature condition of $100{ }^{\circ} \mathrm{C}$ to the low temperature condition of the ice water mixture at $0{ }^{\circ} \mathrm{C}$, and then back to the high temperature condition of $100{ }^{\circ} \mathrm{C}$. During the cooling process, the sample is immersed in the ice water mixture of $0{ }^{\circ} \mathrm{C}$, and the water quickly enters the untreated part and deepened the color of the sample (red frame in Fig. 8), while the water could not immerse the part of the sample treated by SIC- 2 . At the same time, the response of the glaze layer to the temperature change is slower than that of the matrix, in which the temperature changes of the sample surface treated with SIC-2 material is smaller than that of the untreated part of the sample (Fig. 9). After analyzing the curve change equation in the first $20 \mathrm{~h}$, the linear equations of untreated glaze and protected glaze are respectively $\mathrm{y}=-2.2489 \mathrm{x}+44.033$ and $\mathrm{y}=-2.4457 \mathrm{x}+48.779$; the exponential equations of untreated matrix and protected matrix are respectively $\mathrm{y}=38.857 \mathrm{e}^{-0.094 \times}$ and $y=40.213 \mathrm{e}^{-0.092 x}$; the correlation coefficients of the fitted curve equation are respectively $R^{2}=0.9487,0.9481$, 0.9709 and 0.9692 . The addition of the protective materials alleviates the effect of drastic temperature changes on glaze and matrix to some extent. During the heating process, the temperature rise rate of the glaze layer is higher than that of the matrix, while the temperature difference between the glaze layer and the matrix decreases after the treatment.

After comparing the temperature changes of the glaze surface and the matrix protected with SIC-1, SIC-2 and SIC-3 materials under the condition of drastic change of temperature and humidity, the impact of immersion water on the matrix is reduced and the temperature change rate of the glaze and the matrix during the cooling process is slowed down, in which the change of the glaze and the matrix treated with SIC-3 and that of the untreated sample is the smallest.

In order to compare the thermal changes of the samples before and after the addition of the protective materials, the expansion coefficient of the protected samples are measured by the low-temperature thermal expansion instrument from room temperature to $300{ }^{\circ} \mathrm{C}$, as shown in Fig. 10. The addition of SIC-1 and SIC-2 reduces the size deformation of the matrix under the thermal action. At the same time, the expansion variable decreases by $0.014 \%$ and $0.016 \%$ respectively at about $170{ }^{\circ} \mathrm{C}$, while 

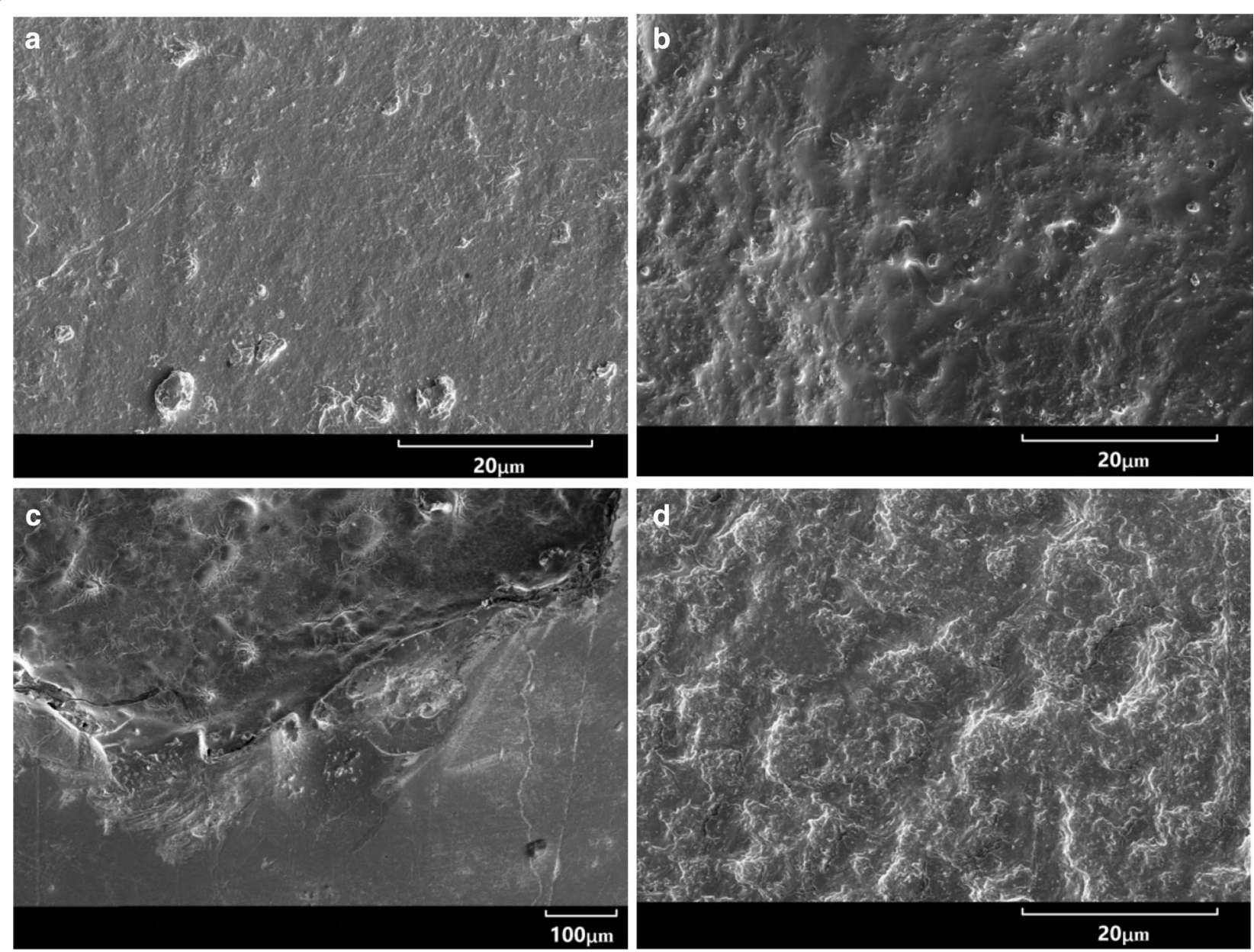

Fig. 7 Microstructure of samples with untreated surface (a), treated with SIC-1 (b), SIC-2 (c) and SIC-3 (d), respectively
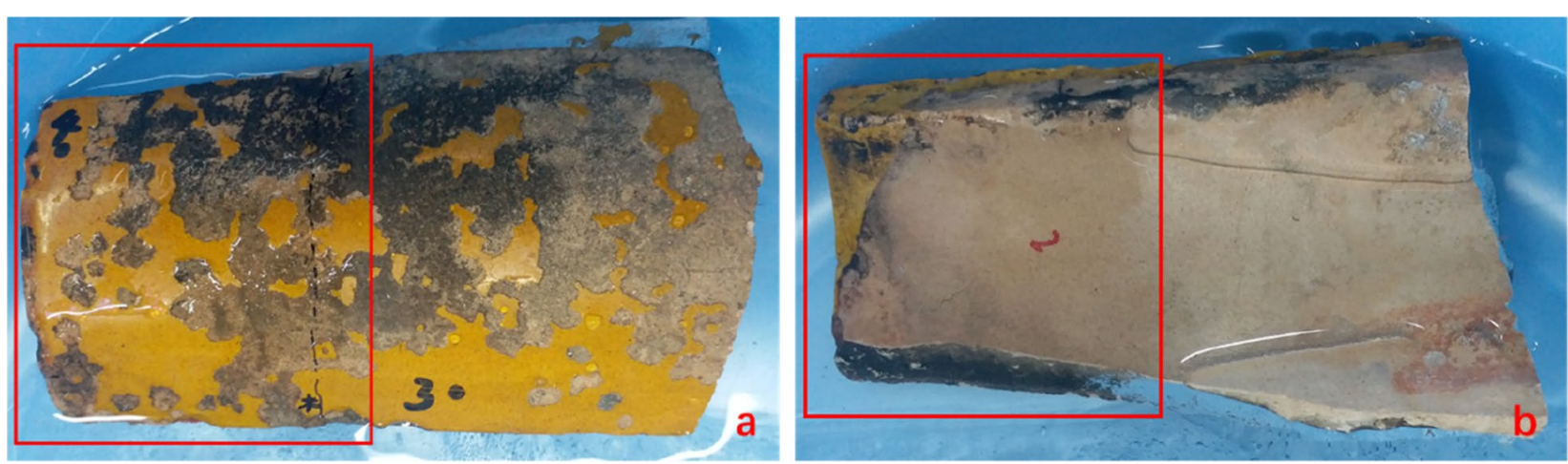

Fig. 8 Surface condition of a glaze sample treated with SIC-2 and then soaked in water a glaze surface $\mathbf{b}$ matrix surface

SIC-3 increases the thermal deformation by about $0.106 \%$. The small change of thermal properties in glazed matrix by the added materials.

The change rate of glaze shedding: Temperature and humidity change cycles are used to detect the shedding status and change rate of glaze surface after adopting protective measures. Figure 11 shows the change of glaze surface at different cycles, and it can be seen that: the glaze of the untreated samples starts to fall off earlier, and after 180 cycles, the glaze layer (the black indicator line 


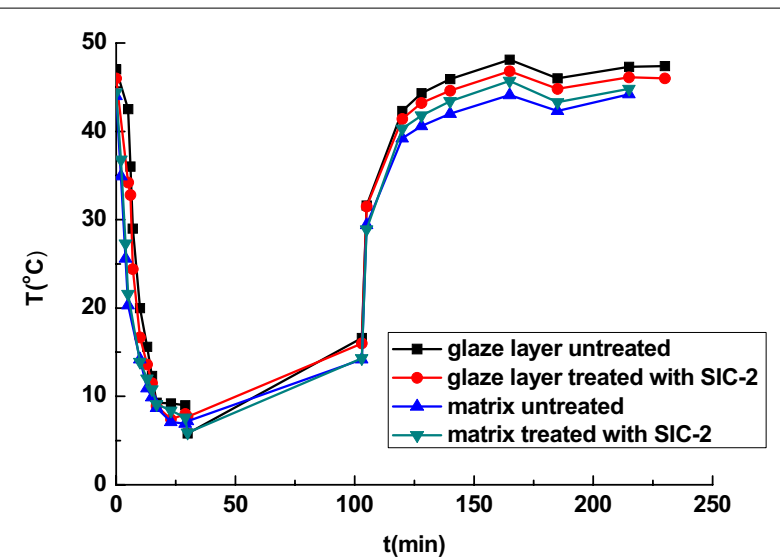

Fig. 9 Surface temperature changing curves of samples in the process of drastic temperature and humidity change

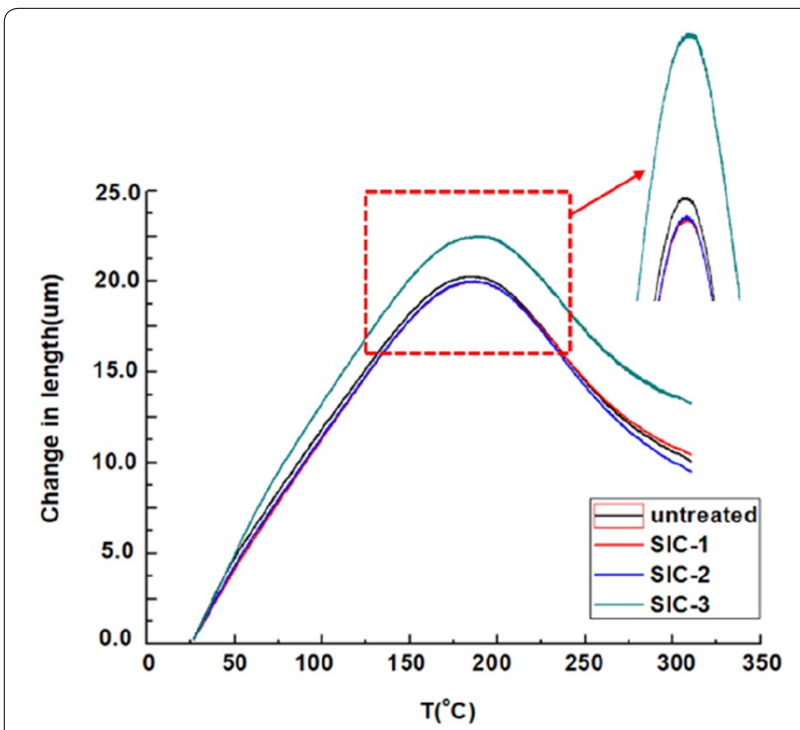

Fig. 10 Thermal expansion coefficient of the treated samples

in Fig. 11c) is seriously detached from the edge interface of the sample. The calculation and analysis for the area of the exfoliated glaze layer in Fig. 12 find that the glaze layer is shedding at the change rate of 0.0647 in the equation $y=0.0647 x-8.5763$ (in the formula, $x$ represents the number of cycles, and y represents the percentage of falling off area to total surface area of glaze layer); with the progressive cyclic numbers, the shedding area of the glaze layer has increased. While comparing the changes of samples treated with protective materials, the shedding rate of glaze surface treated with SIC-1 is increased the most quickly. After the protection of SIC-2 and SIC3 , the appearance time of glaze layer shedding is relatively delayed and a small area of glaze layer falls off at
210 cycles, then the glaze shedding rate was 0.0307 and 0.0535 respectively afterwards. To be more specific, the glaze samples treated with SIC-2 has the lowest rate of glaze loss. As the samples are treated with SIC-3, there is a gradual hydrolysis aging of the protective materials and the white materials appear on the surface of the glaze layer, which changes the color of the glaze to some extent.

The glaze shedding time is delayed and the shedding rate of glaze layer is decreased for the samples after the treatment. Meanwhile, the air permeability and the hydrophobicity of glaze layer and matrix are improved. Among them, the difference between the glaze layer treated with SIC-1 material and the matrix is relatively large, while the difference between the glaze layer and the matrix protected by SIC- 2 and SIC- 3 is relatively small, and the change rate of glaze layer shedding is relatively the least. Additionally, the special attention is the hydrolysis aging of SIC-3 material, which affects the color change of the glaze samples. Comparing the three protective materials, the SIC-2 material exhibits an excellent protective effect, which can delay the shedding process and decrease the change rate of glaze layer preferably.

\section{Conclusion}

After being placed outdoors for five or six hundred years, glazed tiles on ancient buildings in the Beijing Palace Museum suffer a major degradation of glaze shedding. In order to prevent the continuous loss of glaze layer, three protection materials have been selected and the protective properties of these materials on glaze samples have been evaluated. The results show that silicon materials containing fluorine with nanoscale particles can effectively delay the glaze shedding rate, and have a certain degree of protective effect. Specifically including:.

(1) For the protected glaze samples, there is a minor change in the color of the samples protected by fluorosilicate materials SIC-2 with granular distribution of nanoclusters. The hydrophobic property of the matrix can be increased and the difference in the adsorption of water vapor between the matrix and the glaze can be reduced; meanwhile the transmittance of water vapor can be improved.

(2) In the study of the surface temperature change of the samples, the addition of the materials can alleviate the difference induced by drastic temperature change on the glaze surface and the matrix to some extent.

(3) Overall, the addition of the protective materials has reduced the difference between glaze surface and the matrix under the influence of temperature and water, in which SIC-2 can be selected as the most excellent protective material for reducing the glaze shedding speed. 


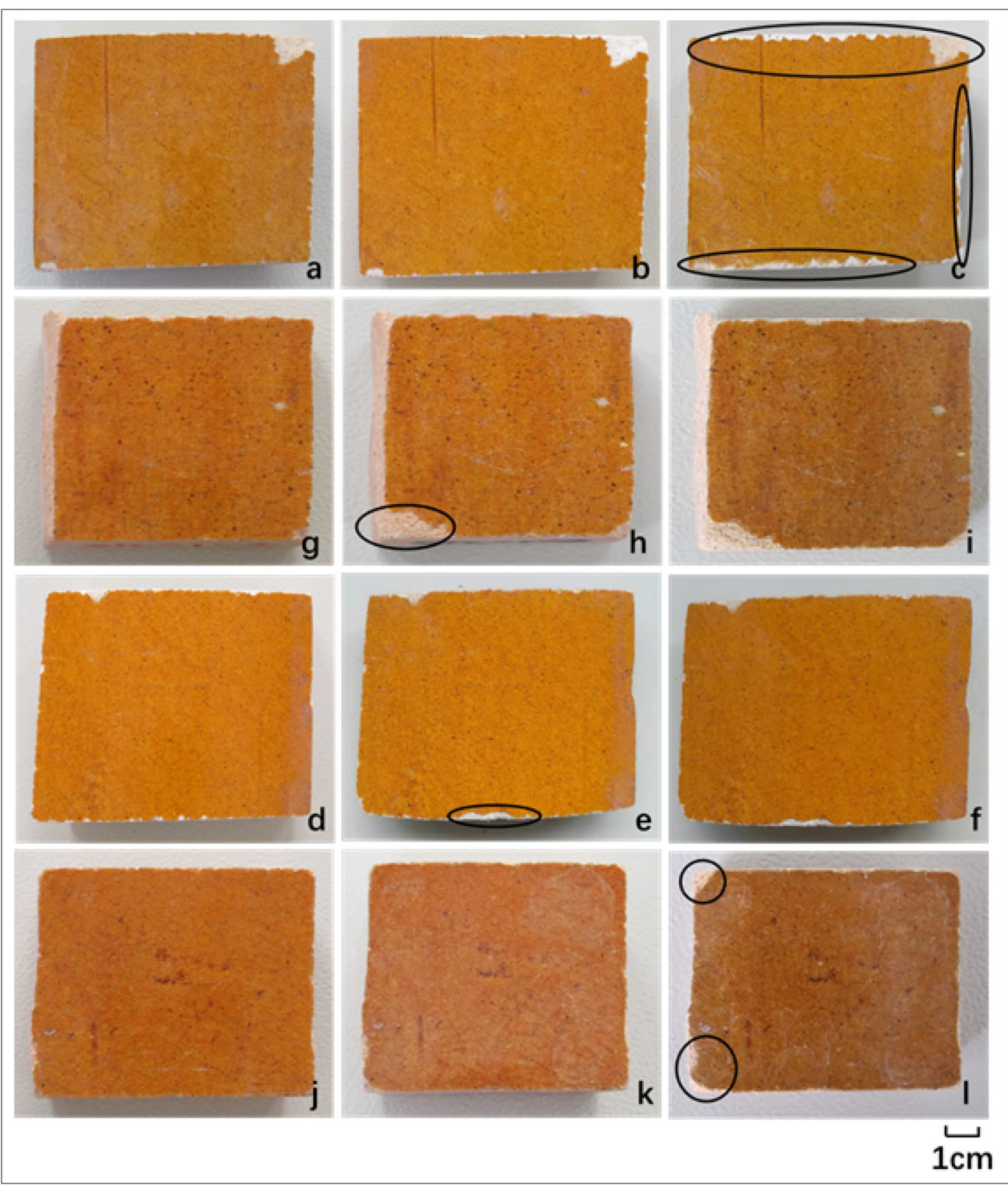

Fig. 11 Glaze surface changes of the samples resulted from drastic cycle changes of temperature and humidity. $\mathbf{a}$ Untreated sample $\mathbf{b}$ untreated sample after 147 cycles $\mathbf{c}$ untreated sample after 180 cycles $\mathbf{d}$ The sample treated with SIC-1 e the samples treated with SIC-1 after 180 cycles $\mathbf{f}$ the samples treated with SIC-1 after 210 cycles $\mathbf{g}$ the sample treated with SIC-2 $\mathbf{h}$ the samples treated with SIC-2 after 210 cycles $\mathbf{i}$ the samples treated with SIC-2 after 250 cycles $\mathbf{j}$ the sample treated with SIC-3 $\mathbf{k}$ The samples treated with SIC-3 after 180 cycles IThe samples treated with SIC-3 after 210 cycles 


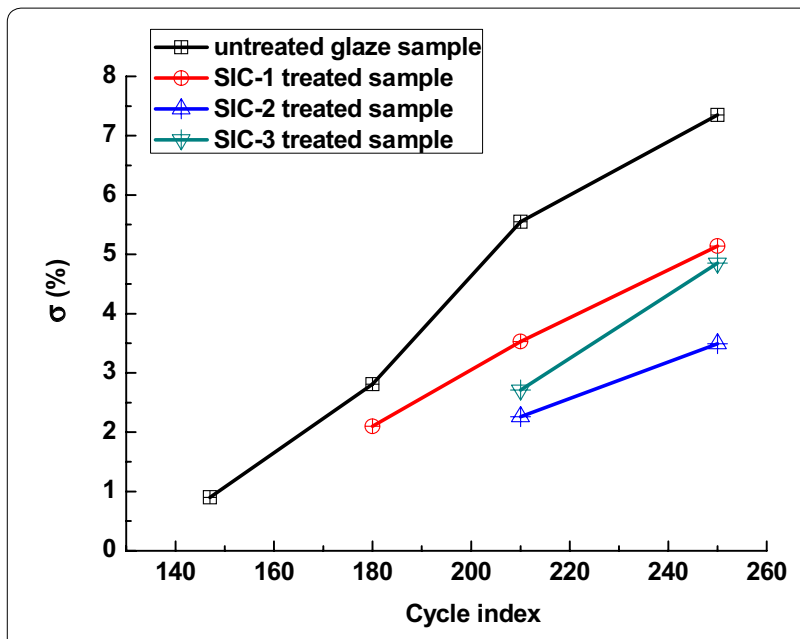

Fig. 12 The glaze shedding rate of samples under drastic cycle changes of temperature and humidity

\section{Abbreviations}

FTIR-ATR: Attenuated total reflection Fourier transformed infrared spectroscopy; SEM-EDX: Scanning electron microscopy with energy dispersive X-ray.

\section{Acknowledgements}

Not applicable.

\section{Authors' contributions}

DA has written the manuscript; JZ and LY have performed all experimental work; PZ and CW have provided the glaze shedding samples and supported the application of protective materials; HL participated in discussions and manuscript writing. All authors read and approved the final manuscript.

\section{Funding}

This research was provided by the project "Research on the protection of the Yangxin Hall in the Palace Museum" supported by the Palace Museum in China.

\section{Availability of data and materials}

The datasets used and/or analyzed during the current study are available from the corresponding authors on reasonable request.

\section{Competing interests}

The authors declare that they have no competing interests.

\section{Author details}

${ }^{1}$ Ancient Ceramics Research Center, Shanghai Institute of Ceramics Chinese Academy of Sciences, Shanghai 200050, China. ${ }^{2}$ College of Cultural Heritage, Northwest University, Xi'an 710069, China. ${ }^{3}$ Palace Museum, Beijing 100009, China. ${ }^{4}$ Institute for the Conservation of Culture Heritage, Shanghai University, Shanghai 200444, China.

Received: 22 November 2019 Accepted: 7 April 2020

Published online: 15 April 2020

\section{References}

1. Li QQ, Liu JY. Glaze technology in ancient Chinese architecture. Beijing: China Architecture \& Building Press; 1987 (in Chinese)

2. Zhao J, Dilraba ADL, Qian R, et al. Study on glaze damage of ancient buildings of Yangxin Hall and Yanxi Hall of Imperial Palace. Scien Conserv Archae. 2020;32:1-12 (in Chinese)

3. Vaz MF, Pires J, Carvalho AP. Effect of the impregnation treatment with Paraloid B-72 on the properties of old Portuguese ceramic tiles. J Cult Herit. 2008;9:269-76.

4. Yu PH, Barclay S, Davis B. Correlating natural ageing and Xenon irradiation of Paraloid ${ }^{\circledR}$ B72 applied on stone. Polym Degrad Stabi. 2003;80:533-41.
5. Vinçotte A, Beauvoit E, Boyard N, Guilminot E. Effect of solvent on PARALOID ${ }^{\circledR B}$ B72 and B44 acrylic resins used as adhesives in conservation. Herit Sci. 2019:7:42.

6. Vicini S, Margutti S, Princi E, Moggi G, Pedemonte E. In situ copolymerization for the consolidation of stone artefacts. Macromol Chem Phys. 2002;203:1413-9.

7. Carretti E, Dei L. Physicochemical characterization of acrylic polymeric resins coating porous materials of artistic interest. Prog Org Coat. 2004;49:282-9.

8. Hui R, Lu ZY. Research on anti-corrosion protection of ancient glaze components in Shan-Shan Guildhall of Luoyang. Tradit Chin Archit Gardens. 2011:4:21-5 (in Chinese).

9. Kronkright D. Alkoxysilanes and the consolidation of stone. J Am Inst Conserv. 2007:46:189-91.

10. Illescas JF, Mosquera MJ. Surfactant-synthesized PDMS/silica nanomaterials improve robustness and stain resistance of carbonate stone. J Phys Chem C. 2011;115:14624-34.

11. Remzova M, Sasek P, Frankeova D. Effect of modified ethyl silicate consolidants on the mechanical properties of sandstone. Constr Build Mater. 2016;112:674-81.

12. Luo HJ, Liu R, Xiao H. Progress in research of crack-free organosilane consolidants for stone conservation. Mater China. 2012;31:1-8 (in Chinese).

13. Illescas JF, Mosquera MJ. Producing surfactant-synthesized nanomaterials in situ on a building substrate, without volatile organic compounds. ACS Appl Mater Interfaces. 2012;4:4259-69.

14. Mosquera MJ, De los Santos DM, Rivas T. Surfactant-synthesized ormosils with application to stone restoration. Langmuir. 2010;26:6737-45.

15. Castelvetro V, Aglietto M, Ciardelli F. Design of fluorinated acrylic-based polymers as water repellent, intrinsically photostable coating materials for stone. ACS Symp Series. 2001;787:129-42. https:/doi.org/10.1021/bk-2001-0787.ch010.

16. Toniolo L, Poli T, Castelvetro V, Manariti A, Chiantore O, Lazzari M. Tailoring new fluorinated acrylic copolymers as protective coatings for marble. J Cult Herit. 2002:3:309-16.

17. Torrisi A. Evaluation of five fluorinated compounds as calcarenite protective. J Cult Herit. 2008:9:135-45.

18. Ciardelli F, Aglietto M, Castelvetro V, Chiantore O, Toniolo L. Fluorinated polymeric materials for the protection of monumental buildings. Macromol Symp. 2000;152(1):211-22.

19. Rosa CL. Testing a fluorinated compound as a protective material for calcarenite. J Cult Herit. 2001:2:55-62.

20. Allesandrini GMA, Aglietto M, Castelvetro V, Ciardelli F, Peruzzi R, Toniolo L. Comparative evaluation of fluorinated and unfluorinated acrylic copolymers as water-repellent coating materials for stone. J Appl Polym Sci. 2000;76:962-77.

21. Sabatini V, Cattò C, Cappelletti G. Protective features, durability and biodegration study of acrylic and methacrylic fluorinated polymer coatings for marble protection. Prog Org Coat. 2018;114:47-57.

22. Kaplan Z, Böke H, Sofuoglu A. Long-term stability of biodegradable polymers on building limestone. Prog Org Coat. 2019;131:378-88.

23. Valipour MN, Birjandi FC, Sargolzaei J. Durable, superhydrophobic, superoleophobic and corrosion resistant coating on the stainless-steel surface using a scalable method. Appl Surf Sci. 2014;283:636-47.

24. Li YY, Zhang RF, Yu H, Chen G, Zhu B, Qiu BW, Zou H, Li XY. Fluorinated nanosilica size effect on hierarchical structure and superhydrophobic properties of the epoxy nanocomposite film. ACS Appl Polym Mater. 2020;2:418-26.

25. Zhao J, Luo HJ, Wang LQ. TEOS/PDMS-OH hybrid material for the consolidation of damaged pottery. Herit Sci. 2013;1:12.

26. Zhao J, Luo HJ, Wang LQ. PDMS-OH/silica nanomaterial as new consolidant for damaged pottery. International Conference on Modern Chemical Technology in the Protection of Cultural Heritage. 2012;261.

27. Hygrothermal performance of building materials and products-Determination of water vapour transmission properties. Berlin: German Institute for Standardization; 2001.

28. Cassie ABD, Baxter S. Wettability of porous surfaces. Trans Faraday Soc. 1944;40:546-50

29. Manna O, Das SK, Sharma R. Superhydrophobic and superoleophobic surfaces in composite materials. Berlin: Springer; 2017. p. 647-86.

\section{Publisher's Note}

Springer Nature remains neutral with regard to jurisdictional claims in published maps and institutional affiliations. 